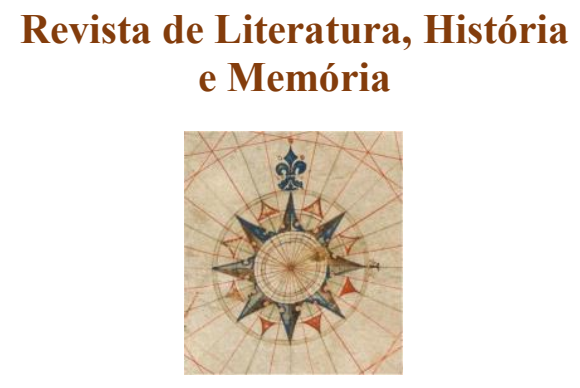

Seção: Pesquisa em Letras no contexto Latino-americano e Literatura, Ensino e Cultura

ISSN 1983-1498

VOL. 17 - No 29 - 2021

U N I O E S T E / CA S C A V E L - p. 111-126

\title{
A LITERATURA AFRO-BRASILEIRA FEMININA ANCESTRALIDADE E RENASCIMENTO IDENTITÁRIO NO CONTO “RENASCENÇA” DE CRISTIANE SOBRAL
}

African-brazilian feminine literature: ancestry and rebirth of identity in the short story «Renascença» of Cristiane Sobral

\section{Wilma dos Santos Coqueiro ${ }^{1}$}

RESUMO: A autora Cristiane Sobral, que fez sua estreia na literatura nos Cadernos Negros, em 2000, já é reconhecida nacionalmente por suas coletâneas de poesias e contos, inserindose na vertente literária afrofeminina por meio das temáticas abordadas e dos pontos de vista em seus textos, que buscam a afirmação da identidade negra. Com personagens fortes e resistentes aos valores hegemônicos da cultura europeia transplantada para o Brasil, suas personagens priorizam suas raízes étnicas ancestrais. Desse modo, nesse artigo, busca-se analisar no conto "Renascença", que integra a coletânea $O$ tapete voador, de 2016, a relação da protagonista, cujo nome é Teresa, com sua ancestralidade e sexualidade, ao não se render às convenções impostas que a pressionam para um embranquecimento étnico. A análise respalda em autores como, entre outros, Bonnici (2007), Duarte (2008), Santos e Wielewicki (2009), Lugones (2014), Ribeiro (2017) e Almeida (2020).

PALAVRAS-CHAVE: Literatura Afro-brasileira, Autoria Feminina; Personagem feminina; Identidade; Ancestralidade.

ABSTRACT: The author Cristiane Sobral, who had her literary debut in Cadernos Negros, in 2000, is already nationally recognized for her collections of poetry and short stories, being part of the Afrofeminine literary side through the themes addressed and the points of view in her texts that seek the affirmation of black identity. With strong characters resistant to the hegemonic values of European culture transplanted to Brazil, her characters prioritize their ancestral ethnic roots. Thus, this article seeks to analyze in the short story "Renascença", which is part of the collection $O$ tapete voador (2016), the relationship of the protagonist, whose name is Teresa, with her ancestry and sexuality, by not surrendering to the imposed conventions that pressure her towards ethnic whitening. The analysis is supported by authors such as Bonnici (2007), Duarte (2008), Santos and Wielewicki (2009), Lugones (2014) Ribeiro (2017) and Almeida (2020), among others.

KEYWORDS: Afro-Brazilian Literature; Female Author; Female Character; Identity; Ancestrality.

\section{CONSIDERAÇÕES INICIAIS: A CRÍTICA FEMINISTA E A LITERATURA AFROFEMININA}

O movimento feminista, em sua luta contra a opressão sexista e definido como uma convicção da igualdade sexual e social entre homens e mulheres, de acordo com Bonnici

\footnotetext{
${ }^{1}$ Professora adjunta da Unespar/Campus de Campo Mourão, PR. Integrante do Grupo de Pesquisa Diálogos Literários e do Grupo de Estudo e Pesquisa em Educação, Diversidade e Cultura - GEPEDIC, ambos da UNESPAR/Campus de Campo Mourão e o Grupo de Pesquisa LAFEB, da Universidade Estadual de Maringá.
} 
(2007), "é um movimento internacional, histórico e culturalmente muito diversificado" (p. 87). Já Silva (2018) enfatiza a reinvindicação de libertação dos padrões e das expectativas comportamentais baseadas na questão de gênero. Articulando luta e militância com fundamentação teórica, para a autora, "o movimento está consolidado como discurso de caráter intelectual, filosófico e político que busca demolir os padrões que conferem base às opressões impostas às mulheres ao longo da história da humanidade" (SILVA, 2018, p. 5).

Costumeiramente, divide-se esse movimento nas denominadas ondas feministas, ou seja, momentos históricos de efervescência de determinadas pautas, sendo que cada onda tem suas especificidades e suas demandas. Se, na Primeira Onda Feminista (entre fins do século XIX e meados do século XX), houve o surgimento do movimento sufragista e a busca por direitos civis, na Segunda Onda Feminista (a partir dos anos de 1950), inicia-se a distinção entre sexo e gênero, pois o "sexo passa a ser entendido como uma característica biológica, e gênero, como uma construção social, um conjunto de papéis impostos à pessoa a depender de seu sexo". (SILVA, 2019, p. 11). Nesse período, prevalecia a crença de que a categoria "mulher" incluiria a mulher negra, prescindindo da questão de raça. Com efeito, para Bonnici (2007), a crítica feminista, entre os anos 70 e 90, não se ocupava de revisões e reescritas em relação à escrita da mulher negra. Ademais, elas também não eram incluídas na crítica feita por homens negros, ou seja, predominava um silenciamento e uma invisibilidade dessas escritoras devido ao equívoco da crítica literária feminista em buscar "universalizar a mulher negra". Devido a isso, houve duras críticas de feministas negras que viam no movimento uma supremacia branca e burguesa que não consideravam, segundo bell hooks ${ }^{2}(2019)$, que ao se ater à opressão sexista, o movimento não reconhecia outros fatores de dominação que determinavam a forma e a intensidade com que os indivíduos eram discriminados e oprimidos.

Assim, devido ao fato de as escritoras negras clamarem "por uma crítica feminista negra, consciente da integração dos sistemas raça, classe e gênero na experiência diária e nos escritos de mulheres negras" (BONNICI, 2007, p. 106-107), a partir da virada dos anos de 1980 e 1990 - após alguns acontecimentos históricos que mudaram o mundo como a Queda do Muro de Berlim (1989), a dissolução da União Soviética (1991) e o fim das ditaduras na América Latina, as feministas da terceira onda buscaram "o reconhecimento das diversas identidades femininas, entendendo que as opressões sociais, mesmo que baseadas em gênero,

\footnotetext{
2 Esse é o pseudônimo da teórica feminista e ativista social americana Gloria Jean Watkins. Ao usar o pseudônimo inspirado no nome da avó materna, em letra minúscula, a autora quer destacar o conteúdo da sua escrita e não sua pessoa. Nesse trabalho, optaremos por seguir a forma usada pela autora, inclusive nas citações e referências.
} 
atingem de maneiras diferentes mulheres que se encontram em diferentes condições" (SILVA, 2019, p. 17). Nesse sentido, após as mulheres negras, lésbicas e pertencentes à classe trabalhadora darem início a um "feminismo identitário", podemos dizer que "o feminismo negro se fortalece e cresce enquanto vertente feminista independente" (SILVA, 2019, p.18).

A luta por um movimento feminista interseccional - que aponta para a necessidade de levar em consideração os diferentes tipos de opressão que as mulheres de diferentes condições vivem, devido às diferenças de classe social e de raça -, teve seus primórdios com as lutas femininas nos EUA. Com críticas às feministas brancas, heterossexuais e de classe média alta - que não contemplavam as negras e lésbicas em suas reivindicações - uma dessas militantes e ativistas dos direitos civis foi a escritora caribenha-americana Audre Geraldine Lorde (19341992), que buscou a afirmação como mulher negra. De acordo com ela, acerca do movimento feminista em curso na década de 80 , as mulheres brancas se concentram "contra a opressão e ignoram a diferença de raça, preferência sexual, classe e idade. Há uma pretensão de homogeneidade de experiência que o termo sororidade abrange, a qual efetivamente não existe" (LORDE, 1988, apud BONICCI, 2007, p. 107).

Esse ideal de solidariedade entre mulheres também é defendido por bell hooks ${ }^{3}(2019)$ que propõe que a luta antirracista também seja travada por mulheres brancas para que seja possível uma aliança com as mulheres multiétnicas. Para isso, não seria necessário eliminar as diferenças e as divergências, mas buscar aprender umas com as outras para que seja possível a construção de uma irmandade e uma solidariedade entre mulheres. Para hooks, as mulheres brancas são oprimidas pelo sexismo, mas o racismo e o privilégio de classe as autorizam a agir como opressoras de outras mulheres. Da mesma forma, em relação aos homens negros, que são vitimados pelo racismo, o sexismo lhes permite oprimir as mulheres. Na avaliação de hooks, embora esses grupos protagonizem lutas de libertação em relação aos seus interesses, também empreendem opressão a outros grupos como, por exemplo, às mulheres negras para as quais não existe o "outro" a ser objetificado e explorado. É nesse sentido, que "o sexismo dos homens negros tem minado a luta pela erradicação do racismo, da mesma forma que o racismo das mulheres brancas tem minado a luta feminista" (hooks, 2019, p. 46). Nesse sentido, o feminismo tem que ser compreendido como um compromisso político porquanto "a teoria feminista teria muito a oferecer se mostrasse às mulheres os caminhos pelos quais o

\footnotetext{
${ }^{3}$ O seu livro Teoria feminista: da margem ao centro, que citamos pela edição brasileira de 2019, foi publicado originalmente em 1984, no início da terceira onda feminista, e traz fortes críticas ao feminismo americano branco, capitaneado por escritoras como Betty Friedan, pela perspectiva unidimensional em relação ao movimento, ao privilegiar as pautas da mulher branca, heterossexual e de classe média, em sua emblemática obra A mistica feminina, de 1963.
} 
racismo e o sexismo se interconectam, em vez de colocá-los um contra o outro ou simplesmente deixar o racismo de lado" (hooks, 2019, p. 92).

Também a socióloga, professora e ativista feminista argentina Maria Lugones (2014), em seu artigo "Rumo a um feminismo descolonial", defende a ideia do gênero como uma imposição colonial, partindo da reflexão acerca do conceito "colonialidade de gênero" (LUGONES, 2014, p. 936) como uma opressão de "gênero racializada" (LUGONES, 2014, p. 939), ao enfatizar que as mulheres negras e indígenas sofrem diferentes formas de opressão em comparação à mulher branca. Nesse sentido, emerge a necessidade de um feminismo decolonial que questione os padrões eurocêntricos. A autora cria, então, o conceito de "subjetividade ativa" para designar a resistência às múltiplas formas de opressão. Para ela, “em nossas existências colonizadas, racialmente gendradas e oprimidas, somos também diferentes daquilo que o hegemônico nos torna. Esta é uma vitória infrapolítica" (LUGONES, 2014, p. 940). Com efeito, a autora tonou-se uma das vozes emblemáticas ao defender uma filosofia feminista interseccional entre gênero e raça, uma vez que conclui que mulheres negras e indígenas não se encontram representadas nem nas categorias universais "mulher", nem em "negro" e "índio", tornando-se, assim, inexistentes, isto é, uma espécie de "categoria vazia".

\footnotetext{
A crítica contemporânea ao universalismo feminista feita por mulheres de cor e do terceiro mundo centra-se na reivindicação de que a intersecção entre raça, classe, sexualidade e gênero vai além das categorias da modernidade. Se mulher e negro são termos para categorias homogêneas, atomizadas e separáveis, então sua intersecção mostra-nos a ausência das mulheres negras - e não sua presença (LUGONES, 2014, p. 935).
}

Em relação ao Brasil, percebe-se que ainda permanecem muitas dificuldades na produção e recepção da literatura negra, uma vez que as grandes editoras privilegiam a publicação de autores brancos e geralmente homens. Se, para as mulheres brancas, as condições para publicar obras ainda são bastante desiguais em relação aos homens brancos, para as escritoras negras, as dificuldades são maiores. Em uma pesquisa recente sobre a produção de autoria feminina, a professora Lúcia Osana Zolin (2019) afirma que entre as escritoras que conseguiram publicar, nessas primeiras décadas do século XXI, em editoras renomadas - como Rocco, Companhia das Letras e Record - 98\% são brancas, $89 \%$ nascidas ou radicadas no eixo Rio-São Paulo e 100\% integram a denominada elite intelectual brasileira, com profissões tais como: jornalistas, professoras universitárias, tradutoras, roteiristas, entre outras. Desse modo, parece-nos condizente à situação de que - no que se 
refere à arte literária no Brasil - poucas são as mulheres que conseguiram romper as condições históricas de gênero, corroborando a afirmação do sociólogo sueco Göran Therborn de que "a longa noite patriarcal da humanidade está chegando ao fim. Está alvorecendo, mas o sol é visível apenas para uma minoria” (THERBORN, 2006, p. 195).

De fato, Zolin argumenta que é preciso "se atentar para a necessidade de popularização das condições de produção e circulação da literatura de autoria feminina, tendo em vista as intersecções travadas entre o gênero da escritora e outras categorias como a de classe, de raça/etnia, de escolaridade etc.” (ZOLIN, 2019, p. 329). É nesse sentido que o professor Thomas Bonnici (2007) ressalta a importância de estudos feministas negros no Brasil em que sejam privilegiadas a voz e a representação de mulheres negras na sociedade e na literatura. De acordo com Ianni (1988, p. 98), "a literatura não só expressa como também organiza uma parte importante da consciência social do negro". O crítico ainda acrescenta que, assim como a política e a religião, entre outras formas de consciência, "ela é uma forma singular, privilegiada, de expressão e de organização das condições e possibilidades da consciência do negro" (IANNI, 1998, p. 98).

Assim, ao se pensar nessa ideia de representação, é válido mencionar, mesmo que de forma breve, os Cadernos Negros, que atendem a uma demanda de literatura não absorvida pelo mercado editorial brasileiro. Mesmo sem muita visibilidade nas livrarias, os Cadernos, com suas publicações regulares de antologias de poemas e contos de autores afro-brasileiros, uma a cada ano, e cujo trabalho editorial é realizada pela Quilombhoje, desde 1978, vêm driblando as dificuldades e buscando dar visibilidade a autores/as afro-brasileiros/as. Dessa forma, como um espaço de resistência literária, social e política, esse veículo tem revelado grandes talentos, sendo muitos autores hoje nacionalmente conhecidos como, entre outros, Cuti, um dos idealizadores da antologia, Conceição Evaristo (cuja primeira publicação foi nos Cadernos, em 1990) e Cristiane Sobral (que estreou na literatura em 2000).

Em relação à literatura negra ou literatura afro-brasileira, há controvérsias em relação à denominação ${ }^{4}$. O estudioso Eduardo Assis Duarte (2008) acredita que a literatura escrita por autores negros passa por um momento rico, não apenas em grandes produções, como também de debates e estudos nas academias. Contudo, ele ressalta que ainda persiste uma questão

\footnotetext{
${ }^{4}$ Embora os conceitos, muitas vezes, sejam usados como sinônimos, há autores que preferem uma ou outra denominação. Octávio Ianni (1988) geralmente fala em literatura negra. Eduardo Assis Duarte (2008) usa mais o termo literatura afro-brasileira. Cuti (2010), por exemplo, fala em literatura negro-brasileira, por entender que "a literatura negro-brasileira nasce na e da população negra que se formou fora da África, e de sua experiência no Brasil" (p. 44). Já Santos e Wielewicki (2009) optam pelo termo literatura-afro-brasileira, por entenderem que essa é "uma literatura empenhada em resgatar a ancestralidade africana" (p. 342). Nesse trabalho, usaremos os termos de forma indistinta por entendermos que ambos englobam os requisitos necessários à conceituação dessa literatura, como entre outros, autoria, tema, perspectiva, ponto de vista e questões de linguagem.
} 
bastante perversa quando se pergunta se essa literatura realmente existe, fato já discutido por Marina Colasanti (1997), no ensaio "Por que nos perguntam se existimos?", em relação à literatura de autoria feminina.

Colasanti afirma que esse tipo de pergunta é feita, de fato, pela sociedade, que deseja colocar a literatura de minorias - ela se refere à literatura de autoria feminina, mas podemos relacionar com a afro-brasileira também - sob suspeição, colocando em dúvida sua existência. Para a autora, "ao me perguntar, sobretudo a mim escritora, se o que eu faço existe realmente, está afirmando que, embora possa existir, sua existência é tão fraca, tão imperceptível, que é bem provável que não exista" (COLASANTI, 1997, p. 37). Em relação à literatura afrobrasileira-Duarte ressalta que "essa literatura não só existe como se faz presente nos tempos e espaços históricos de nossa constituição enquanto povo, não só existe como é múltipla e diversa" (DUARTE, 2008, p. 11).

Já em relação à conceituação da literatura de autoria negra, Santos e Wielewicki abordam o apagamento do negro na representação literária, afirmando que "é como se os negros, forçados a cruzar os mares como escravos, tivessem deixado na costa africana todos os seus sistemas, formas, elementos e práticas culturais e religiosas" (SANTOS; WIELEWICKI, 2009, p. 343). As autoras ainda argumentam que existem alguns critérios de definição dessa vertente literária. São eles: “o critério étnico (ligação da obra à origem negra ou mestiça do autor); o critério temático (conteúdo literário relacionado aos temas referentes à cultura afro-brasileira), e o que chamaremos de critério de transgressão (o texto como forma de reivindicação e resistência)" (SANTOS; WIELEWICKI, 2009, p. 342). Isso faz com que alguns escritores possam ser considerados afro-brasileiros por um critério ou outro.

Eduardo Assis Duarte (2008), por sua vez, aponta que a conceituação da literatura afro-brasileira se dá a partir da interação entre cinco elementos que a caracterizam, cuja conjunção leva à constatação da "existência de uma literatura negra em sua plenitude" (p. 21). São eles: temática negra; a autoria, pois a escrita deve ser proveniente de um autor afrobrasileiro; ponto de vista, ou seja, "assunção de uma perspectiva e, mesmo de uma visão de mundo, identificada à história, à cultura, logo a toda a problemática inerente à vida desse importante segmento da população" (DUARTE, 2008, p.12); no âmbito da linguagem, uma “discursividade específica, marcada pela expressão de ritmos e significados novos e, mesmo um vocabulário pertencente às práticas oriundas da África e inseridas no processo transculturador em curso no Brasil”' (p. 12); e, por fim, a formação de um público leitor afrodescendente como um elemento específico dessa literatura.

Para Duarte, a questão da autoria é um dos critérios que mais tem gerado debates e 
controvérsias, pois é preciso entender a autoria não só em relação à condição negra do/a escritor/a, "mas na condição traduzida em constante discursiva integrada à materialidade da construção literária" (p.15).

\section{“TINHA LÁ SUA DOSE DE REBELDIA”: A FICÇÃO DE CRISTIANE SOBRAL}

Em relação à atriz e escritora Cristiane Sobral, nascida em 1974 no Rio de Janeiro e radicada atualmente em Brasília, e que, conforme já mencionado anteriormente, estreou em 2000 na literatura, publicando textos nos Cadernos Negros, podemos dizer que seus contos e poesias abordam a mulher negra como depositária de uma cultura ancestral e de uma memória coletiva, ao cumprir em sua produção os critérios apontados por Santos e Wielewicki (2009) e Duarte (2008). Em relação a obras de ficção, além de ter publicado na coletânea Olhos de Azeviche: dez escritoras negras que estão renovando a literatura brasileira, organizada por Vagner Amaro, em 2017, também é autora das coletâneas de contos Espelhos, miradouros, dialéticas da percepção (2011) e O tapete voador (2016) ${ }^{5}$.

Formada em educação artística e mestre em teatro, Cristiane Sobral, além de ministrar aulas de teatro, também é pesquisadora sobre a estética no teatro negro e militante das questões que envolvem a negritude. A autora revela em entrevista ao site AfroPress (2013, n.p.) que "a literatura negra tem seu tecido próprio" e aconselha jovens negros que gostam de escrever a lerem muito e ocuparem seu lugar ao sol porquanto escrever e publicar, em meio ao padrão eurocêntrico ainda dominante, configura-se como atos de afirmação e luta. Para Sobral, antologias como os Cadernos Negros foram essenciais para a construção de valores que apontam para a identidade e etnicidade negra, fazendo com que a literatura negra no Brasil esteja associada diretamente à militância.

Escrever é reescrever. A literatura negra tem um tecido próprio, apresenta a nossa subjetividade, fala também de um sujeito construído no coletivo, resgata os valores da negritude brasileira, da sua própria cultura, dos meios de criação e reflexão sobre a experiência negra. Há um resgate positivo da

\footnotetext{
${ }^{5}$ Entre as coletâneas, com publicação de contos da autora, tanto Olhos de Azeviche: dez escritoras negras que estão renovando a literatura brasileira quanto $O$ tapete voador, foram publicadas pela editora Malê, cuja linha editorial é voltada para propiciar visibilidade a obras de autores africanos e afro-brasileiros. Já Espelhos, miradouros, dialéticas da percepção também foi publicado por uma editora sem destaque no campo literário, a Dulcina Editora, no Distrito Federal. Isso reforça o que foi dito anteriormente acerca da dificuldade de inserção das escritoras negras no campo cultural. Em relação a esse mercado editoral, Sobral avalia que, após o sucesso de sua obra poética Não vou mais lavar os pratos, com mil livros vendidos em seis meses, de forma improvisada, a segunda edição da obra já encontra-se inserida em uma política de distribuição das editoras, mas ainda de forma muito tímida.
} 
nossa etnicidade, da nossa identidade, um ponto de vista diferente do apresentado nas versões dominantes (SOBRAL, 2013, n.p.).

Em relação a essas representações que buscam uma resistência a valores hegemônicos da cultura branca, é fundamental o conceito de "lugar de fala", discutido pela ativista feminista, filósofa e escritora Djamila Ribeiro (2017). De acordo com a autora, a tentativa de universalização das pautas feministas, das primeiras ondas do movimento, propiciou uma desumanização das mulheres negras ao relegá-las ao silenciamento de suas angústias e demandas. Para a autora, "existe um olhar colonizador sobre nossos corpos [negros], saberes, produções e, para além de refutar esse olhar, é preciso que partamos de outros pontos" (RIBEIRO, 2017, p. 37), uma vez que "mulheres negras, nessa perspectiva, não são nem brancas e nem homens, e exerceriam a função de Outro do Outro (RIBEIRO, 2017, p. 37). Nesse sentido, são rentáveis as considerações de Lugones (2014) acerca da necessidade de descolonização do gênero como uma práxis. Para a filósofa argentina, esse embate significa “decretar uma crítica da opressão de gênero racializada, colonial e capitalista heterossexualizada visando uma transformação vivida do social (LUGONES, 2014, p. 940).

Nesse sentido, como contraponto à reflexão de Conceição Evaristo acerca da representação negativa da mulher negra na literatura brasileira que "ainda surge ancorada nas imagens de seu passado escravo, de corpo procriação e/ou corpo-objeto de prazer do macho senhor" (EVARISTO, 2005, p. 52), a coletânea de contos de Sobral, intitulada O tapete voador, publicada em 2016, traz personagens femininas vivenciando experiências ou situações que as fazem (re)afirmar os valores ligados à etnicidade e à negritude. Geralmente são mulheres jovens e bonitas que - ao contrário de grande parte da ficção afrodescendente encontram-se em situação de ascendência social e intelectual, tem curso superior e buscam um pertencimento à ancestralidade africana.

Santos (2018), ao analisar as políticas do corpo em Cristiane Sobral, chega à conclusão de que o corpo emerge na obra da autora como um elemento político, aproximando-se do conceito de "subjetividade ativa", proposta pelo "feminismo decolonial" de Lugones (2014). Santos acrescenta ainda que "o corpo feminino negro político é pensado dentro de um contexto histórico cultural, a partir de dois grandes temas: violência e resistência, associados a discussões sobre violência e suas consequências para a autoestima da mulher negra" (SANTOS, 2018, p.37). Esse fato pode ser observado em vários contos que trazem temas referentes à escrita negra, definidos por Figueiredo (2009, apud SANTOS, 2018), como a violência, as relações afetivas e a história e memória ancestrais. No que diz 
respeito às relações afetivas, a autora expõe a solidão da mulher negra, que é bastante recorrente na sociedade.

Com efeito, no conto "O tapete voador", homônimo à coletânea, Bárbara é graduada e tem um ofício importante em uma multinacional, do qual abre mão ao receber a proposta indecorosa do diretor da empresa - que é negro -para "minimizar aspectos genéticos desagradáveis" (SOBRAL, 2016, p. 10) como seu cabelo crespo. Em "O elevador de serviço", Malena é uma artista que vive em um prédio de luxo e é vitima de racismo no elevador, quando uma senhora branca lhe pergunta se ela não conhecia alguém, assim como ela, que poderia trabalhar em seu apartamento como doméstica. Contudo, apesar do estarrecimento diante da cena, sentindo-se "conectada com sua ancestralidade e sua arte" (SOBRAL, 2016, p. 30), Malena não se abala e acaba dando uma resposta apropriada à senhora, enfatizando a importância do conhecimento para se evitar equívocos oriundos de "séculos de herança escravocrata" (SOBRAL, 2016, p. 29). Em "Nkala: um relato de bravura", Sobral remonta ao período escravocrata para contar a história de Nkala, uma princesa do Congo, que "sabia que não nascera para ser escravizada" (SOBRAL, 2016, p. 33), e morre lutando contra seus

algozes que "com chibatadas insanas, rasgaram sua pele até os órgãos e ossos" (SOBRAL, 2016, p. 35). Dessa forma, por meio da morte física, ela, "liberta da matéria, foi acolhida pelos seus ancestrais rumo a Aruanda, o paraíso da liberdade perdida” (SOBRAL, 2016, p. 35). Nesse trabalho, será analisado o último conto da coletânea, intitulado "Renascença", que traz uma protagonista que, assim como muitas outras da autora, resiste à pressão pelo embranquecimento e pela adesão à cultura europeia hegemônica em terras brasileiras.

\section{"TRAÇOS DE ESFINGE AFRICANA": A REPRESENTAÇÃO DA PERSONAGEM FEMININA NO CONTO "RENASCENÇA"}

No conto, intitulado "Renascença", a autora traz a história de Teresa, uma psicóloga realizada em sua profissão, muito devota à congregação cristã, que sonhava em casar-se e formar uma família. Contudo, apesar de toda a sua religiosidade, Teresa começa a perceber que a igreja, além de uma instituição capitalista, é um lugar de discriminação racial. Por se orgulhar e manter suas características étnicas - com seus cabelos crespos sempre ressaltados ela acaba por se sentir rejeitada pelos rapazes que frequentavam a igreja: "Teresa gostava muito de sua igreja, mas seu corpo negro também sentia naquele ambiente o peso do preconceito, da discriminação" (SOBRAL, 2016, p. 98).

Teresa, apesar de "bela, elegante, charmosa, era sem duvida uma mulher interessante 
na forma e no conteúdo" (SOBRAL, 2016, p. 95) - era preterida em relação às mulheres brancas (e as que amenizavam os traços negros com alisamentos e outros procedimentos estéticos) que eram "exibidas como troféus" (SOBRAL, 2016, p. 95). Independente economicamente e consciente em relação aos padrões de beleza e de comportamentos impostos, Teresa, ao contrário das moças que conhecia, "não aceitaria um homem que tentasse mudar sua natureza, isso não" (SOBRAL, 2016, p.96).

A respeito dessa situação de rejeição vivenciada pela protagonista do conto, bell hooks (2010), em "Vivendo de Amor", desvela que, mesmo não sendo um assunto que se fale abertamente, a solidão é um fantasma que ronda a trajetória de mulheres negras, pois "numa sociedade racista, capitalista e patriarcal, os negros não recebem muito amor" (hooks, 2010, n.p.). Segundo ela, essa situação remonta à escravidão quando o maior desafio era a sobrevivência e, para isso, a repressão de emoções e sentimentos se constituía como uma estratégia para continuidade da existência. De acordo com a autora, pessoas negras ainda carregam as feridas emocionais oriundas da escravidão que interferem na capacidade de afeto, pois "elas sabiam, por experiência própria, que na condição de escravas seria difícil experimentar ou manter uma relação de amor" (hooks, 2010, n.p.). Para hooks, expressar emoções e buscar aprender e se reconhecer na sua vida interior, como observamos na vivência da personagem do conto, é essencial para mulheres negras, uma vez que contribui com a definição de suas necessidades a serem preenchidas no contato com outras pessoas e, consequentemente, com o desejo de viver plenamente.

Apesar da sua crença em Deus, Teresa percebia que na sua igreja lhe era vedada a função de protagonismo. O conto, a partir do ponto de vista de um narrador onisciente, por meio do discurso indireto livre, desvela os pensamentos e questionamentos da personagem em relação ao comportamento esperado das mulheres, pois suas amigas diziam que as mulheres deveriam depender economicamente dos maridos para serem aceitas: "Nenhuma delas questionava o machismo e o racismo. Machismo, racismo? Onde?"'(SOBRAL, 2016, p.96).

Nesse sentido, a respeito desse racismo como parte da ordem social brasileira, são pertinentes as considerações do advogado e estudioso da teoria social, Sílvio Almeida (2020) que, em sua obra Racismo estrutural, publicada na coleção Feminismos Plurais, coordenada por Djamila Ribeiro, argumenta que o racismo é sempre estrutural porque incorpora a organização econômica, política e social de forma indissolúvel. Almeida apresenta duas teses

\footnotetext{
${ }^{6}$ Embora bell hooks, em seu artigo, faça uma análise das pessoas afro-americanas e as marcas emocionais que carregam em decorrência da escravidão, as suas considerações condizem perfeitamente com a sociedade brasileira, pois os dois países vivenciaram, de forma semelhante, esse sistema de opressão e exploração humana.
} 
que estão interligadas: a primeira é que a sociedade contemporânea pode ser concebida a partir de noções como raça e racismo e a segunda diz respeito à necessidade de conhecimento da teoria social para a efetiva compreensão desses conceitos. Desse modo, o autor busca evidenciar que "o racismo é uma manifestação normal de uma sociedade, e não um fenômeno patológico ou que expressa algum tipo de anormalidade" (ALMEIDA, 2020, p. 21). É nesse sentido, então, que o racismo opera ao prover "o sentido, a lógica e a tecnologia para a reprodução das formas de desigualdade e violência que moldam a vida social contemporânea" (ALMEIDA, 2020, p. 21).

Com efeito, podemos observar no conto a forma como a própria instituição religiosa, “onde a fé e o capitalismo andavam de mãos dadas e a prosperidade costumava estar exclusivamente vinculada aos bens materiais" (SOBRAL, 2016, p. 96), comunga com práticas racistas ao relegar as mulheres negras ao papel "de servas do senhor", pois "não eram consideradas belas" (SOBRAL, 2016, p. 95). Dessa forma, podemos entender que o racismo, como forma de dominação, é algo inerente à estrutura social e que contamina as demais instituições. De acordo com Almeida, o racismo institucional, baseado em padrões de raça que mantém uma hegemonia branca no poder, "faz com que a cultura, os padrões estéticos e as práticas de poder de um determinado grupo tornem-se o horizonte civilizatório do conjunto da sociedade" (ALMEIDA, 2020, p. 40). No conto de Sobral, essa hegemonia racial se materializa na imagem de Jesus Cristo com "os ditos olhos azuis e a pele clara" (SOBRAL, 2016, p. 96) que contribui, mesmo que indiretamente, para a discriminação, de forma sistemática, das pessoas negras no âmbito religioso.

Apesar da situação de exclusão em que vive, Tereza opta por não se render às convenções que a aprisionam a um "destino de mulher". Na sua busca por responder às suas necessidades emocionais, essa vivência solitária é rompida em uma madrugada quando acordou "com o corpo em chamas, cheio de urgências" (SOBRAL, 2016, p. 97). Aqui, além da representação do corpo feminino em sua plenitude, há uma verbalização dos desejos femininos, sem pejo ou censura. É nessa perspectiva que hooks (2010) afirma a relevância de a mulher negra descolonizada definir suas experiências de acordo com sua vida interior. $\mathrm{Na}$ concepção da autora, "se passarmos a explorar nossa vida interior, encontraremos um mundo de emoções e sentimentos. E se nos permitirmos sentir, afirmaremos nosso direito de amar interiormente" (hooks, 2010, n.p.).

Nesse sentido, de modo geral, ao corpo feminino, foi imposto um silenciamento ao longo da história, como salienta Perrot (2013) em "Os silêncios do corpo da mulher", o qual “pesa primeiramente sobre o corpo, assimilado à função anônima e impessoal da reprodução. 
[...] Mas esse corpo exposto, encenado, continua opaco. Objeto dos olhos e do desejo, fala-se dele. Mas ele se cala. As mulheres não falam, não devem falar dele” (p. 13).

Em relação ao corpo da mulher negra, essa opacidade é ainda mais perversa, uma vez que, desde os primórdios da escravidão, em suas representações na literatura de autoria masculina, tem sido exposto como sinônimo do desejo sexual do outro ${ }^{7}$. A ruptura com esse olhar do outro tem sido cada vez mais frequente na ficção de autoria feminina contemporânea. No conto aqui discutido, comparece esse corpo feminino com uma representação da mulher como sujeito, que valoriza os seus traços étnicos afro-brasileiros e reivindica seus desejos inatos. O sociólogo francês Alain Touraine corrobora a ideia da conquista da subjetividade feminina associada à atividade sexual, ao destacar "a importância extrema do corpo como espaço de relação consigo mesmo e de construção de si" (TOURAINE, 2011, p. 57).

Por isso, a personagem feminina, ao ser interpelada pelos instintos sexuais, foge aos padrões ao sair de casa - sentindo-se "majestosamente bela" - com um vestido curto vermelho, saltos altos, acessórios como brincos, colar e pulseiras, com "maquiagem delicada a realçar seus traços de esfinge africana" (SOBRAL, 2016, p.97). Além desse pertencimento étnico reafirmado pela personagem, a sua jornada nessa madrugada tão peculiar, a levará ao encontro com seu pertencimento religioso e cultural. Ao se deparar, devido ao som que parecia um chamado, a uma casa branca - cujas portas estavam abertas - Teresa se acha diante de um Jesus Cristo negro, "parecido com Zumbi”, herói negro morto no Quilombo de Palmares, em 1695, resistindo à escravidão. Para ela, o fundamental é que "ali de braços abertos, o Jesus Cristo negro sorria. Não era escravo, não estava no tronco, não havia marcas de sofrimento no seu corpo. Reinava" (SOBRAL, 2016, p.98), ou seja, naquele espaço ornado com flores, com uma mesa farta de frutas e comidas, e pessoas vestidas de branco, predominava o protagonismo negro que ela jamais encontrara na sua igreja cristã: “ $O$ ambiente estava cheio de sorrisos, liberdade, havia dança, gente branca, negra, crianças, turbantes, vida, prazer, enfim. Não havia o peso do pecado e da culpa" (SOBRAL, 2016, p. 98).

É nessa tenda espírita que, além do encontro com sua ancestralidade africana ao se tornar médium, e a umbanda - religião de matriz africana - entrar em "sua vida para ficar, com sua magia e seu encantamento" (SOBRAL, 2016, p. 99), a personagem finalmente

\footnotetext{
7 Em relação a essa "outremização" de personagens femininas negras em textos de autoria masculina, são emblemáticas personagens como Rosa, de A escrava Isaura (1875), de Bernardo Guimarães, Rita Baiana, de $O$ Cortiço (1890), de Aluísio de Azevedo, e Gabriela, protagonista de Gabriela, cravo e canela (1958), de Jorge Amado. Nesses romances, essas personagens, de origem africana, são representadas de forma preconceituosa e estereotipada, desde a imagem física sedutora à personalidade hipersexuada.
} 
encontra seu grande amor, um homem negro e alto, "com sua pele de azeviche, como se estivesse à sua espera" (Idem, p. 98). Ele sorriu para ela assim que a viu entrar e lhe cumprimentou, dizendo que era bem-vinda.

Com o tempo, e a relação afetiva entre eles seguindo seu curso natural, os dois se casam e celebram a união na religião de matriz africana: "na ocasião, ela surgiu lindamente negra, única, com seu vestido branco ricamente ornamentado nas cores de seu orixá. Foram três dias de comemoração regadas a muita alegria, afeto, dança e música" (SOBRAL, 2016, p. 99, grifos meus). Segundo Santos (2018) - ao retomar a frase de bell hooks de que "o amor cura" - o pertencimento da personagem é concretizado também pela reciprocidade do sentimento afetivo. Para a estudiosa, "na humanização da personagem, a autora atribuiu-lhe o direito à afetividade, como também à escolha do seu parceiro, aspectos pertinentes à literatura negrofeminina" (SANTOS, 2018, p. 202).

Assim, ao final da narrativa, a personagem sente-se feliz e realizada. $O$ seu renascimento - quando vivencia "a dor do seu nascimento aos trintas e quatro anos de idade" (SOBRAL, 2016, p. 99) - como uma espécie de epifania, se constrói a partir do encontro com os laços espirituais e o compromisso com a ancestralidade: "Ela renasceu em um local onde reinavam o orgulho das matrizes africanas, os mistérios da natureza e o corpo negro, totalmente integrado, sem maniqueísmos de bem e mal” (SOBRAL, 2016, p. 99).

De acordo com Santos (1986), a memória e a coletividade são elementos fundamentais na construção da subjetividade humana. Para ela, o indivíduo "é constituído por elementos coletivos, representações deslocadas das entidades genitoras, míticas ou divinas e ancestrais ou antepassados (de linhagem ou família) e por uma combinação de elementos que constituem sua especificidade, ou seja, sua unidade individual" (SANTOS, 1986, p. 203). Nesse sentido, a ideia de ancestralidade é um elemento essencial na constituição da identidade da personagem no conto. Ao sair de uma igreja cristã de matriz europeia e ingressar no terreiro de umbanda, ou seja, numa religião negro-brasileira, Teresa vivencia, de forma profunda e autêntica, uma experiência de encontro com sua ancestralidade africana. A sua iniciação na religião de matriz africana, além de inscrevê-la em uma ordem metafísica, propicia-lhe uma nova identidade, não dissociada da corporeidade negra. A personagem constrói sua subjetividade como uma "mulher para si", com afirmação da liberdade e da responsabilidade, como nos propõe Touraine (2011), ao ingressar em um espaço em que pode viver plenamente a sua negritude. 


\section{CONSIDERAÇÕES FINAIS}

Nesse trabalho, procurou-se mostrar que a autora Cristiane Sobral, em consonância com a militância negrofeminina, comparece na ficção afro-feminina do século XXI como uma voz decolonial marcante na defesa da identidade negra, ligada à ancestralidade e à memória coletiva. Ao reivindicar um "lugar de fala" para a mulher negra, sua literatura se apresenta, no cenário contemporâneo, permeada pela consciência política, ideológica e estética ligada à afro-brasilidade. Com efeito, suas personagens - combativas e resistentes - lutam para manter suas raízes étnicas e culturais, mesmo sofrendo todas as imposições da cultura europeia ainda bastante impregnada na sociedade brasileira. Nesse sentido, como Lugones aponta, persiste ainda um "lócus fraturado" comum a todas às mulheres colonizadas. Por isso, "é nas histórias de resistência na diferença colonial onde devemos residir, aprendendo umas sobre as outras" (LUGONES, 2014, p. 948, grifo da autora).

Desse modo, pode-se afirmar que a ficção de Sobral funciona como uma revisão dos estereótipos do cânone literário nacional e seu silenciamento da mulher negra ao contar uma história do ponto de vista da mulher negra, que busca reverter a imagem pejorativa construída sobre ela pela história colonial e pela literatura de autoria masculina. De acordo com Santos e Wielewicki (2009), essa literatura que "nasce como uma resistência contra as indicações de discriminação do negro em nossa sociedade" (p.346), assume algumas de suas funções essenciais, quais sejam: "Conscientizar; comunicar em particular o sentimento do negro; afirmar a identidade da negritude; reencontrar a verdadeira imagem; evidenciar uma intencional atitude de resistência" (SANTOS; WIELEWICKI, 2009, p. 346 ), entre outras.

\section{REFERÊNCIAS}

ALMEIDA, Sílvio. Racismo estrutural. São Paulo: Sueli Carneiro; Editora Jandaíra, 2020.

BONNICI, Thomas. Teoria e crítica literária feminista: conceitos e tendências. Maringá: EDUEM, 2007.

COLASANTI, Marina. Por que nos perguntam se existimos. In: SHARPE, Peggy (org.) Entre resistir e identificar-se: para uma teoria prática na narrativa brasileira de autoria feminina. Florianópolis: Editora Mulheres; Goiânia: editora da UFG, 1997.

CUTI. Literatura negro-brasileira. São Paulo: Selo Negro Edições, 2010.

DUARTE, Eduardo de Assis. Literatura afro-brasileira: um conceito em construção. Estudos de Literatura Brasileira Contemporânea, $n^{\circ}$. 31. Brasília, janeiro-junho de 2008, p. 11-23. 
EVARISTO, Conceição. Da representação à auto-apresentação da mulher negra na literatura brasileira. Revista Palmares. Brasília, ano 1, n. 1, p. 52-57, ago. 2005.

hooks, bell. Teoria feminista: da margem ao centro. Tradução Rainer Patriota. São Paulo: Perspectiva, 2019.

hooks, bell. Vivendo de amor. Tradução Maísa Mendonça. Portal Géledes. 2010. Disponível em: https://www.geledes.org.br/vivendo-de-amor. acesso 30 nov. 2020.

IANNI, Octavio. Literatura e consciência. In: Revista do Instituto de Estudos Brasileiros. Edição Comemorativa do Centenário da Abolição da Escravatura, nº 28. São Paulo: USP, 1988.

LUGONES, Maria. Rumo a um feminismo descolonial. Tradução de Juliana Watson e Tatiana Nascimento In: Estudos Feministas, Florianópolis, 22(3): 320, setembro-dezembro/2014. p. 935-952.

PERROT, Michele. Os silêncios do corpo da mulher. In: MATOS, Maria Izilda de; SOILET, Rachel (orgs.) O corpo feminino em debate. São Paulo: Editora Unesp, 2003.

SANTOS, Célia Regina \& WIELEWICKI, Vera Helena Gomes. "Literatura de autoria de minorias étnicas e sexuais". In: BONNICI, Thomas \& ZOLIN, Lúcia Osana (orgs.). Teoria Literária: Abordagens históricas e tendências contemporâneas. 3. ed. Maringá: Eduem, 2009. p. $189-199$

SANTOS, Juana Elbein dos. Os Nagô e a morte: pàde, àsèsè e o culto Egun na Bahia. Petrópolis, RJ: Vozes, 1986.

SANTOS, Mirian Cristina. Intelectuais Negras: prosa negro-brasileira contemporânea. Rio de Janeiro: Malê, 2018.

SILVA, Jacilene Maria. Feminismo na atualidade: a formação da quarta onda. Recife: Independently published, 2019.

SOBRAL, Cristiane. O tapete voador. Rio de Janeiro: Malê, 2016.

SOBRAL Cristiane. Nova expressão da literatura negra, para Cristiane Sobral, escrever é resistir. Entrevista ao AfroPress, 07/03/2013. Disponível em: http://www.afropress.com/post.asp?id=14519, acesso 19 ago. 2020.

RIBEIRO, Djamila. O que é lugar de fala? Belo Horizonte (MG): Letramento, 2017.

TOURAINE, Alain. O Mundo das Mulheres. Tradução Francisco Morás. 3. ed. Petrópolis: Vozes, 2011.

THERBORN, Göran. Sexo e poder: a família no mundo, 1900-2000. Tradução Elizabete Dória Bilac. São Paulo: Contexto, 2006. 
ZOLIN, Lúcia Osana. Literatura de autoria feminina. In: BONNICI, Thomas; ZOLIN, Lúcia Osana (orgs.). Teoria literária: Abordagens históricas e tendências contemporâneas. 4. ed. Maringá: Eduem, 2019. p. 319-330.

Recebido: 05/10/2020

Aprovado: 18/01/2021 